\title{
Critical success factors associated with time performance in prefabricated construction
}

\author{
Mingyue Zhao $^{1}$ \\ ${ }^{1}$ Sayre School Lexington, United States
}

\begin{abstract}
Prefabricated construction becomes an increasingly important construction mode especially for buildings that require a short construction time. The construction of Huoshenshan Hospital shows how efficient prefabricated construction could be. In order to provide a clearer blueprint for how to improve time performance in prefabricated construction, this paper identifies 13 important critical success factors associated with time performance and groups them into five categories - project planning and design, supply chain, techniques, teamwork, and external influences. The findings of this paper provide a better understanding of time management in prefabricated construction, which can help to develop appropriate strategies to improve productivity.
\end{abstract}

\section{Introduction}

Unlike conventional construction which is entirely built upon construction site, prefabricated construction is a new type of construction in which factory-made components are transported to construction site and then assembled together [1]. In fact, nowadays many countries including Britain, America, Singapore, France, and China pay more attention to and put more resources on the development as well as the utilization of prefabricated construction [2]. One of the most recognized benefits of prefabricated construction is that it's sustainable [3], and less greenhouse gas is produced during a process of prefabricated construction. Given the fact that our earth is experiencing a harsh climate change right now, prefabricated construction can be an effective alternative to conventional construction technique. There are many other benefits we can obtain from the adoption of this new way of construction as well. For example, fewer workers are needed for a construction project that takes advantage of prefabrication [4]. Additionally, prefabricated construction provides us with a cleaner and more organized construction site [5] and the amount of construction waste is reduced as well under the implementation of prefabrication [6].

Among all these advantages, reduction in time is one of the most important ones since it implies better productivity and greater efficiency. In a situation that requires fast construction of a building, this feature (i.e., time reduction) is valued more than ever. Xiaotangshan Hospital built in Beijing, China in 2003 and Huoshenshan Hospital built in Wuhan, China in 2020 are two great examples of prefabricated construction. In response to the rapid spread of SARS and COVID-19, Xiaotangshan hospital was built in 8 days [7] and Huoshenshan Hospital was built in 10 days with the capacity of 1,000 beds [8], which is like a miracle to a lot of people. Indeed, prefabricated construction as well as many other factors are the important players behind these projects.

In the past, many researchers identified the critical success factors in prefabricated construction in general; but only a few of them had a major focus on the time performance. As a result, one research question is askedWhat are the factors that influence time performance in prefabricated construction? In order to answer this question, this paper aims to identify the critical success factors associated with time performance in prefabricated construction project.

\section{Literature review of the critical success factors associated with time performance}

The idea of critical success factors became official in the 1980s [9]. Critical success factors are defined as the key areas of a project that can contribute to its success and help to reach even exceed project manager's expectation [9]. Since they are influential players in a project, it becomes important for researchers to identify, understand, and analyze those factors. Having a better knowledge of those factors can potentially help industries make further adjustments and improvements to prefabricated construction.

By searching the keywords - "prefabricated construction", "off-site construction", "modular integrated construction", "prefabricated construction management", "prefabricated construction time", "construction time", "critical success factors", and "barriers to prefabricated construction"- the critical success factors associated with time performance are 
identified and grouped into five categories, which are project planning and design, supply chain, techniques, teamwork, and external factors. Five categories as well as the factors under each one of them are discussed and explained in this paper as shown in Table1. The point is to provide a clearer blueprint for time performance in prefabricated construction.

Table1. critical success factors associated with time performance

\begin{tabular}{|c|c|c|}
\hline Categories & Factors & References \\
\hline \multirow{3}{*}{$\begin{array}{c}\text { Project Planning and } \\
\text { Design }\end{array}$} & Detailed drawing & {$[11][15]$} \\
\hline & Well-organized schedule & {$[10][11]$} \\
\hline & Lead-in times during early stages & {$[14]$} \\
\hline \multirow{3}{*}{ Supply Chain } & Transportation availability & {$[10][11][21]$} \\
\hline & Manufacturing capability & {$[10][12][14]$} \\
\hline & Standardization of factory-made components & {$[10][12]$} \\
\hline \multirow{3}{*}{ Techniques } & Availability of workers with professional training & {$[10][11][12][13]$} \\
\hline & The usage of technology in prefabricated manufacturing & {$[14][15]$} \\
\hline & The usage of communication technologies & {$[16][17][18]$} \\
\hline \multirow{2}{*}{ Teamwork } & Coordination among participants from each stage & {$[11][12][19]$} \\
\hline & Participation of key members at all stages & {$[11][20]$} \\
\hline \multirow{2}{*}{ External Influences } & Governmental support & {$[10][12]$} \\
\hline & Natural environment & {$[10][15]$} \\
\hline
\end{tabular}

\subsection{Project planning and design}

The first category-project planning and design — stands for "the schematic design phase of a project" [22]. Most if not all prefabricated construction projects start with this stage. As a result, project planning and design are important since they serve as a foundation for everything else.

Three critical success factors are identified and grouped into this category. The first one is detailed drawing. Construction activity is primarily based on engineering and architectural drawings. For example, factories need drawings to produce components with proper size, and construction workers need drawings to understand how they should assemble those components. Drawings with good details and clarifications can be understood by contractors easily; as a result, they can start their tasks as soon as possible without wasting anytime [15]. If the drawings have no specifications, contractors might make serious mistakes or spend more time understanding the process - either outcome will influence the time performance in a negative way.

The second factor is well-organized schedule. Scheduling is directly related to time performance, and it plays an important role throughout the entire construction project. Time scheduling serves as an outline of a project. If the schedule is organized in which it optimizes the time and arranges the tasks orderly, the construction will be carried out more efficiently and time could be saved in this way [23]. On the contrary, if the schedule is disorganized and hard to implement, productivity will be negatively influenced.

The third critical success factor associated with time performance is lead-in times during early stages. Longer lead-in times can influence designers and contractors in a negative way since it makes the planning process unnecessarily longer [24]. On the contrary, if the designers can shorten the lead-in times by finalizing their designs and plans early [14], the overall construction time can be reduced as well.

\subsection{Supply chain}

The second category — supply chain — represents "a series of processes involved in the production and supply of goods" [25]. The supply chain of prefabricated construction is especially complicated since it contains numerous stages [26]. As a result, it is identified as one of the key categories that have a profound influence on time performance in prefabricated construction projects.

In this paper, three critical success factors are grouped into this category. The first one is manufacturing capability. Prefabricated construction project is closely related to manufacturing capability since it always requires a large number of factory-made components [14]. In order to complete a prefabricated construction project within a short period of time, factories with large capability are needed since they can produce and store more construction components at a time. However, due to the fact that there might not be enough factories that match the requirements for prefabricated manufacturing [27], the sources become more limited. With the help of competent manufacturers, construction time can be effectively reduced.

The second critical success factor that influences time performance is the standardization of factory-made components. Prefabricated construction can be very complex since it involves the assembly of individual components [20]. Moreover, the assembly of components is important for prefabricated construction project because the building might have some safety issues if one part is not well-connected. Without the standardization of factory-made components, companies might produce components that have different interfaces. As a result, the assembly of components becomes even more difficult and time-costing. On the contrary, if there are industrial standardizations of prefabricated components, the 
processes of manufacturing and assembling are simplified. As a result, the construction workers can put the components together easily no matter which company those components came from [20]. Time could be saved if all components are standardized.

The third one is transportation availability. Prefabricated construction requires the transportation of factory-made components to the actual construction site. Transportation can be difficult and time-consuming since manufacturing companies are far away and most prefabricated components are heavy and have a big volume [3]. This implies that in order to save transportation time, it's recommended to choose manufactures that are located at a place where transportation is convenient. For example, Huoshenshan Hospital is at Caidian district in Hubei, where lots of related factories are located. This is the main reason why all construction components could be shipped to the construction site on time.

\subsection{Techniques}

The third category - technique-represents the effective utilization of certain advanced technologies during the process of prefabricated construction. By taking advantage of those techniques, productivity can be improved, and the overall construction can be completed within a shorter period of time [20].

In this research, three critical success factors are classified into this category. The first one is the availability of workers with professional training [10, 11, 12, 13]. Even though the large components of the building are manufactured in the factory, skillful workers are still required on construction site since they need to assemble those large components according to the drawings. However, different from conventional construction, the joints of each component are complicated so it requires specific skills to connect them. Workers with professional training know how to do this right; as a result, they are able to do it quickly and correctly. On the contrary, workers don't have any experience or training about how to put together those components would take longer to finish the task.

The second critical success factor for time performance is the usage of technology in prefabricated manufacturing $[14,15]$. For a project that requires mass production in a factory, technology is more efficient than human labor most of the time, and that's the reason why assembly line has gradually changed into machinery line. The utilization of technology affects productivity in a positive way [15]. Manufacturing works can be completed by machines/technologies within a shorter period of time. Since prefabricated construction relies on off-site manufacturing more than conventional construction does, the reduction in manufacturing time has a huge impact on the overall performance of the construction.

The third critical success factor for time performance is the usage of communication technologies. Prefabricated construction project includes various stages, from design to manufacture to transportation to construction [3]. As a result, a great deal of information is generated and needed to be transferred during a prefabricated construction project. The utilization of effective communication technologies such as BIM, robots, database software makes it easier to save, share, and synchronize the information. Everyone in the project can get the first-hand information right away by taking advantage of those communication technologies. As a result, time is saved and the construction project can be completed more quickly. For example, the construction of Huoshenshan Hospital used information and communication technologies such as BIM and 5G internet [28], which facilitates the communications among project participants.

\subsection{Teamwork}

The fourth category-teamwork-represents how project participants work together in unity. Prefabricated construction is complicated since it contains various stages - from project design to production to transportation to assembly [3]. Each stage is implemented by different entities such as designers and contractors. As a result, it becomes crucial for them to develop a good and profound relationship with each other.

Two critical success factors are grouped into this category. The first one is the coordination among participants from each stage. As mentioned above, prefabricated construction encompasses multiple stages [3]. Each team performs its unique work, but all of their works are closely associated with each other's. For example, only when the design team finishes the drawings and scaling, can the factory start the mass production of components. If one team fails to do its work correctly, every other team and the entire project will be influenced by that. As a result, good communications and coordination are required in order to complete the construction correctly and on time [29]. The construction of Huoshenshan Hospital involved the contributions from numerous teams and companies including the Third Bureau of China Construction Company, China Railway Construction, China Mobile, etc. [28]. All of them cooperated with each other in order to complete the task. Time was used efficiently, and the construction was completed within 10 days.

The second critical success factor in this category is the participation of key members at all stages. Multiple teams are required in a prefabricated construction project [3]. They might not know each other, but the works they need to perform are closely related. As a result, it becomes important to build a linkage among teams, and through the participation of key members at all stages, connection could be built effectively [20]. For example, fabricators can give suggestions on the scaling of components during the design stage [20], so that the design team can provide drawings that are practical. Problems on constructability for fabricators and contractors could be prevented, and construction delay can be avoided as well.

\subsection{External Influences}

The last category-external influences-stands for the critical success factors that are related to external 
environment of the construction project. External influences can either positively or negatively affect the time performance of prefabricated construction project.

This study identifies two external influences that play an important part in time management. The first one is governmental support. Government support is crucial to the implementation of a construction project, especially when that project is based on prefabrication [10]. Because prefabricated construction is relatively new compared with conventional construction, it needs more help and support from governments. For example, government could advertise for prefabricated construction so that more customers would accept the products. Additionally, if a government carries out more laws and policies that support and promote the utilization of prefabricated construction, the whole construction process will be smoother and more efficient since lots of obstacles can be eliminated under governmental help. In fact, the lack of governmental policies is one of the key factors that stop prefabricated construction from prospering [14]. The construction project of Huoshenshan Hospital was under the leadership of Wuhan Urban and Rural Construction Bureau [30]; it held important meetings and gathered necessary workforce in a timely way. Due to the block out of COVID-19, many highways were closed. But the government opened "green channel" for the transportation of construction-related materials [28], so that everything needed for the building of Huoshenshan Hospital could be sent to the construction site in time. As a result, with the help of the government, construction duration was significantly reduced.

The second external influence is natural environment. Compared with conventional construction, prefabricated construction relies less on natural environment [3]. That's because components for prefabricated construction project are manufactured in factories under controlled conditions. However, after the components get transferred to the construction site, workers still need to put them together. As a result, natural environment - such as climate, weather, temperature, and topography-becomes a nonnegligible factor that has the power to influence the overall time performance. For example, if it snows heavily, then the construction workers might need to take days off, which is likely to result in construction delay.

\section{Conclusion}

This paper is dedicated to identify and categorize the critical success factors associated with time performance in prefabricated construction. Five categories-project planning and design, supply chain, techniques, teamwork, and external influences - as well as the factors under each one of them are discussed and explained in this paper. We use the example of Huoshenshan Hospital, a well-known emergency hospital built in 10 days in response to COVID-19, to illustrate the practices of these important factors in reality. The findings reported here shed light on the factors that influence time performance in prefabricated construction; they also help us to understand why Huoshenshan Hospital could be built in 10 days. Additionally, the study suggests that stakeholders should take advantage of those critical success factors, such as coordination among participants from each stage and the standardization of factory-made components, in order to achieve high efficiency and productivity in a prefabricated construction project in the future.

This paper is simply a good start; further researches need to be carried out in order to explain how we should implement those factors and turn theory into actual practice. Researchers can explore the application of advanced technologies during the design phase. For example, question like how to use AI technologies to automatically create the standardized design drawing can be explored in the future. In manufacturing and installation phases, it's recommended to develop robots and machines to improve the productivity. Moreover, how to effectively train construction workers is still a problem that requires more studies. There are many things we can do in the future.

\section{References}

1. Jiang, Lei, Zhongfu Li, Long Li, and Yunli Gao. "Constraints on the promotion of prefabricated construction in China." Sustainability 10, no. 7 (2018): 2516.

2. Shen, Liyin, Xiangnan Song, Ya Wu, Shiju Liao, and Xiaoling Zhang. "Interpretive Structural Modeling based factor analysis on the implementation of Emission Trading System in the Chinese building sector." Journal of Cleaner Production 127 (2016): 214-227.

3. Li, Zhengdao, Geoffrey Qiping Shen, and Xiaolong Xue. "Critical review of the research on the management of prefabricated construction." Habitat international 43 (2014): 240-249.

4. Wang, Jiayuan, Hongping Yuan, Xiangping Kang, and Weisheng Lu. "Critical success factors for on-site sorting of construction waste: a China study." Resources, conservation and recycling 54, no. 11 (2010): 931-936.

5. Mao, Chao, Qiping Shen, Liyin Shen, and Liyaning Tang. "Comparative study of greenhouse gas emissions between off-site prefabrication and conventional construction methods: Two case studies of residential projects." Energy and Buildings 66 (2013): 165-176.

6. Jaillon, L., Chi-Sun Poon, and Y. H. Chiang. "Quantifying the waste reduction potential of using prefabrication in building construction in Hong Kong." Waste management 29, no. 1 (2009): 309-320.

7. Wang, Zhaojing, Hao Hu, and Jie Gong. "Framework for modeling operational uncertainty to optimize offsite production scheduling of precast components." Automation in Construction 86 (2018): 69-80.

8. Miller, Roger, Mike Hobday, Thierry Leroux-Demers, and Xavier Olleros. "Innovation in complex systems industries: the case of flight simulation." Industrial and corporate change 4, no. 2 (1995): 363-400. 
9. Rockart, John Fralick. "The changing role of the information systems executive: a critical success factors perspective." (1980).

10. Wuni, Ibrahim Yahaya, and Geoffrey Qiping Shen. "Critical success factors for modular integrated construction projects: a review." Building Research \& Information (2019): 1-22.

11. Wuni, Ibrahim Yahaya, Geoffrey Qiping Shen, and Bon-Gang Hwang. "Risks of modular integrated construction: A review and future research directions." Frontiers of Engineering Management (2020): 1-18.

12. Gan, Xiaolong, Ruidong Chang, Jian Zuo, Tao Wen, and George Zillante. "Barriers to the transition towards off-site construction in China: An Interpretive structural modeling approach." Journal of cleaner production 197 (2018): 8-18.

13. Gibb, Alistair GF. "Standardization and preassembly-distinguishing myth from reality using case study research." Construction Management \& Economics 19, no. 3 (2001): 307-315.

14. Mao, Chao, Qiping Shen, Wei Pan, and Kunhui Ye. "Major barriers to off-site construction: the developer's perspective in China." Journal of Management in Engineering 31, no. 3 (2015): 04014043

15. Hasan, Abid, Bassam Baroudi, Abbas Elmualim, and Raufdeen Rameezdeen. "Factors affecting construction productivity: a 30 year systematic review." Engineering, Construction and Architectural Management (2018).

16. Walker, Derek HT. "An investigation into construction time performance." Construction Management and Economics 13, no. 3 (1995): 263274.

17. Kamar, K. A. M., M. Alshawi, and Z. Hamid. "Barriers to industrialized building system (IBS): The case of Malaysia." In In BuHu 9th International Postgraduate Research Conference (IPGRC), Salford, United Kingdom. 2009.

18. Kamar, Kamarul Anuar Mohamad, and Zuhairi Abd Hamid. "Supply chain strategy for contractor in adopting industrialized building system (IBS)." Australian Journal of Basic and Applied Sciences 5, no. 12 (2011): 2552-2557.

19. Azhar, Salman, Maulik Y. Lukkad, and Irtishad Ahmad. "An investigation of critical factors and constraints for selecting modular construction over conventional stick-built technique." International Journal of Construction Education and Research9, no. 3 (2013): 203-225.

20. Wuni, Ibrahim Y., Geoffrey QP Shen, and Abba Tahir Mahmud. "Critical risk factors in the application of modular integrated construction: a systematic review." International Journal of Construction Management (2019): 1-15.

21. O'Connor, James T., William J. O'Brien, and Jin Ouk Choi. "Critical success factors and enablers for optimum and maximum industrial modularization." Journal of Construction Engineering and Management 140, no. 6 (2014): 04014012.

22. "National Council of Architectural Registration Boards." NCARB. Accessed August 26, 2020. https://www.ncarb.org/.

23. Nasirian, Araz, Mehrdad Arashpour, Babak Abbasi, and Ali Akbarnezhad. "Optimal work assignment to multiskilled resources in prefabricated construction." Journal of Construction Engineering and Management 145, no. 4 (2019): 04019011.

24. Goodier, Chris I., and Alistair GF Gibb. "Barriers and opportunities for offsite in the UK." In Systematic Innovation in the Management of Projects and Processes. Abdul Samad Kazi (ed), cib Helsinki international joint symposium, pp. 148-158. 2005.

25. The Oxford Dictionary. Oxford: Oxford University Press, 1992.

26. Arashpour, Mehrdad, Yu Bai, Guillermo Arandamena, Alireza Bab-Hadiashar, Reza Hosseini, and Pushpitha Kalutara. "Optimizing decisions in advanced manufacturing of prefabricated products: Theorizing supply chain configurations in off-site construction." Automation in Construction 84 (2017): 146-153.

27. Hong, Jingke, Geoffrey Qiping Shen, Zhengdao Li, Boyu Zhang, and Wanqiu Zhang. "Barriers to promoting prefabricated construction in China: A cost-benefit analysis." Journal of cleaner production 172 (2018): 649-660.

28. "Youku - Apps on Google Play." Google. Google. Accessed August 26, 2020. https://play.google.com/store/apps/details? $\mathrm{id}=$ com.y ouku.phone.

29. Polat, Gul. "Factors affecting the use of precast concrete systems in the United States." Journal of Construction Engineering and Management 134, no. 3 (2008): 169-178.

30. "Home." CGTN. Accessed August 26, 2020. https://www.cgtn.com/. 